\title{
Expression of Cell Adhesion Molecules, CD44s and E- Cadherin, and Microvessel Density in Carcinoid Tumors
}

\author{
Xiaoping Sun, M.D., Ph.D., Yun Gong, M.D., Mark S. Talamonti, M.D., M. Sambasiva Rao, M.D. \\ Department of Pathology (XS, YG, MSR) and Surgery (MST), Northwestern University Medical School, \\ Chicago, Illinois
}

\begin{abstract}
Although all carcinoids are potentially malignant, their biologic behavior is quite variable. Currently there are no reliable morphological criteria to predict metastatic potential. Cell adhesion molecules, such as CD44 and E-cadherin, are considered important in regulating invasion and metastasis of tumors. Also, angiogenesis has been shown to be associated with tumor growth and progression. In this study, we examined 51 carcinoids, including 13 carcinoids with known lymph node and/or visceral metastasis, for expression of CD44s (the standard form of CD44) and E-cadherin by immunohistochemistry. We found that $55 \%$ and $37 \%$ of carcinoids were negative for CD44s and E-cadherin, respectively. Carcinoids with lymph node and/or visceral metastasis were significantly more frequently negative for CD44s than were those without demonstrated metastasis $(P=.030)$. Ten of 11 tumors with lymph node metastasis lacked CD44s $(P=.022)$, whereas E-cadherin was negative in only $3(P=.975)$. Additionally, we analyzed microvessel density to evaluate the role of tumor angiogenesis in the tumor behavior. Carcinoid tumors in general demonstrated high microvessel density $(160 \pm 82 /$ five $200 \times$ fields), irrespective of location and with and without metastasis. These results suggest that loss of CD44s, but not E-cadherin, may be a useful predictor of metastatic potential of carcinoid tumors.
\end{abstract}

KEY WORDS: Angiogenesis, Carcinoid tumor, CD44, Cell adhesion molecules, E-cadherin, Metastasis, Microvessel density.

Mod Pathol 2002;15(12):1333-1338

Copyright $\odot 2002$ by The United States and Canadian Academy of Pathology, Inc.

VOL. 15, NO. 12, P. 1333, 2002 Printed in the U.S.A.

Date of acceptance: August 7, 2002.

Address reprint requests to: M. Sambasiva Rao, M.D., Department of Pathology, Northwestern University Medical School, 303 E. Chicago Avenue, Chicago IL 60611; e-mail: s-rao@northwestern.edu; fax: (312) 503-8240.

DOI: 10.1097/01.MP.0000038464.44522.90
Although most carcinoid tumors exhibit benign behavior, a significant proportion of them act in a malignant fashion and are difficult to manage $(1,2)$. Evaluation of the malignant potential of a carcinoid tumor remains problematic. Primary tumor site, tumor size, level of urinary 5-hydroxyindoleacetic acid, and specific histologic growth patterns have been touted as useful prognostic factors. However, information regarding the utility of these data in predicting behavior is controversial $(3,4)$. Recently, several other tumor markers such as Ki-67, Bcl-2, and p53; cell adhesion molecules; and tumor angiogenesis have been explored as possible prognostic markers (5-10).

Cell adhesion molecules play a critical role in a variety of processes such as embryonic development, extracellular matrix binding, hematopoiesis, lymphocyte homing, cell migration, and tumor metastasis (11-14). CD44 and E-cadherin (ECAD) are two important adhesion molecules that have been extensively studied. CD44 is a large family of cell surface transmembrane glycoproteins whose members differ in their extracellular domains as a result of alternative splicing $(12,15)$. The data regarding the role of CD44 in neoplasia are controversial in regard to whether CD44 acts as a growth/invasion- promoting molecule or a tumor suppression cofactor $(16,17)$. The standard or hematopoietic form of CD44 (CD44s) is a receptor for hyaluronan and is highly expressed on human lymphocytes. Expression of CD44s has been shown to be associated with good prognosis in patients with bronchial carcinoids $(8,9)$. ECAD is a calcium-dependent transmembrane protein. Decreased expression of ECAD has been correlated with regional lymph node metastasis in squamous cell carcinomas (18) and with poor prognosis in gastric and colorectal cancers (19-21). Expression of ECAD in carcinoid tumors has not been reported previously. In this study, we have investigated the relationship of CD44s expression, ECAD expression, and microvessel density to the biological behavior of carcinoid tumors. 


\section{MATERIALS AND METHODS}

Archival materials of 51 carcinoid tumors from the lung $(n=20)$, large bowel $(n=11)$, appendix ( $n$ $=7)$, small bowel $(n=6)$, stomach $(n=5)$, ovary ( $n$ $=1)$, and kidney $(n=1)$ that were accessioned in the surgical pathology files at our institution from 1996 to 2000 were used in this study. In 26 cases, regional lymph nodes were available for evaluation. Immunohistochemical studies were performed on formalin-fixed, paraffin-embedded tissue with monoclonal antibodies directed against the standard form of CD44 (CD44s, DAKO), ECAD (Zymed), and CD34 (Immunotech) using a standard avidinbiotin-peroxidase method (22). Briefly, $4-\mu \mathrm{m}$-thick paraffin sections were dewaxed and treated with $1 \%$ $\mathrm{H}_{2} \mathrm{O}_{2}$ in methanol for 30 minutes to block endogenous peroxidase activity. Antigen retrieval was performed in a microwave oven (pressure cooker) with Antigen Retrieval Citra microwave solution (BioGenex). The sections were incubated for 30 minutes with normal nonimmune serum to eliminate nonspecific staining. The antibody (1:200 dilution for anti-CD44s and 1:500 dilution for anti-ECAD) was then applied for 2 hours at room temperature. For anti-CD34, manufacturer-prediluted antibody solution was used and reaction was carried out in a Ventana machine (Tucson, AZ) for 32 minutes at $37^{\circ} \mathrm{C}$. Antigen was detected with a biotin-labeled secondary antibody and avidin-biotin peroxidase technique using $3^{\prime}, 3^{\prime}$-diaminobenzidine as the chromogen. Sections were counterstained with hematoxylin. Negative controls were performed by omitting the primary antibodies. For CD44s and ECAD, immunohistochemical reactions were graded as positive or negative based on the staining intensity of the membrane as well as on the number of cells stained (23). Tumors with no reactivity, weak reactivity, or moderate to strong reactivity in $<10 \%$ of tumor cells were graded as negative, whereas those with a moderate to strong degree of reactivity in $\geq 10 \%$ tumor cells were considered positive. For microvessel density, microvessels highlighted by anti-CD34 were counted in each case from the five most vascular, nonoverlapping fields ( $20 \times$ objective and $10 \times$ ocular, Nikon, 0.74 $\mathrm{mm}^{2}$ per field as measured with an ocular micrometer) in a section. The averages of the five counts were used for statistical analyses.

For statistical analyses, $\chi^{2}$ and Fisher exact tests using the Prophet 5.0 statistics program (BBN System \& Technology) were applied, and a $P$ value of $<.05$ was considered significant.

\section{RESULTS}

Fifty-one carcinoid tumors included in this study were obtained from 30 females and 21 males, ranging in age from 17 to 80 years (median, 53 y). Except

TABLE 1. Immunohistochemical Detection of CD44s and ECAD in Carcinoid Tumors

\begin{tabular}{|c|c|c|c|c|c|c|c|c|}
\hline Substance & Lung & S. Bowel & L. Bowel & Appendix & Stomach & Ovary & Kidney & Total, $n(\%)$ \\
\hline CD44s+ & 11 & 1 & 6 & 2 & 2 & 1 & 0 & $23(45)$ \\
\hline CD44s- & 9 & 5 & 5 & 5 & 3 & 0 & 1 & $28(55)$ \\
\hline ECAD+ & 11 & 4 & 8 & 5 & 2 & 1 & 1 & $32(63)$ \\
\hline ECAD- & 9 & 2 & 3 & 2 & 3 & 0 & 0 & 19 (37) \\
\hline Total & 20 & 6 & 11 & 7 & 5 & 1 & 1 & $51(100)$ \\
\hline
\end{tabular}

S. Bowel, small bowel; L. Bowel, large bowel.

TABLE 2. Expression of CD44s and ECAD versus Tumor Size and Patients' Age

\begin{tabular}{|c|c|c|c|c|c|c|}
\hline \multirow{2}{*}{ Substance } & \multicolumn{2}{|c|}{ Tumor Size $(\mathrm{cm})^{a}$} & \multicolumn{2}{|c|}{ Age (y) } & \multicolumn{2}{|c|}{ Metastasis } \\
\hline & $>2$ & $<2$ & $\geq 50$ & $<50$ & + & - \\
\hline CD44s+ & 8 & 12 & 14 & 9 & 2 & 21 \\
\hline CD44s- & 12 & 12 & 19 & 9 & 11 & 17 \\
\hline$P$ value & 0.507 & & 0.603 & & 0.030 & \\
\hline $\mathrm{ECAD}+$ & 12 & 14 & 19 & 13 & 10 & 22 \\
\hline ECAD- & 8 & 10 & 14 & 5 & 3 & 16 \\
\hline$P$ value & 0.909 & & 0.301 & & 0.220 & \\
\hline Total & 20 & 24 & 33 & 18 & 13 & 38 \\
\hline
\end{tabular}

${ }^{a}$ Data on tumor size were available in 44 of the 51 cases.

TABLE 3. Expression of CD44s and ECAD versus Tumor Lymph Node Status

\begin{tabular}{|c|c|c|c|c|c|c|c|c|c|c|}
\hline \multirow{2}{*}{ Substance } & \multicolumn{2}{|c|}{ Lung } & \multicolumn{2}{|c|}{ Small Bowel } & \multicolumn{2}{|c|}{ Large Bowel } & \multicolumn{2}{|c|}{ Appendix } & \multicolumn{2}{|c|}{ Total } \\
\hline & $\mathrm{LN}+$ & $\mathrm{LN}-$ & $\mathrm{LN}+$ & $\mathrm{LN}-$ & $\mathrm{LN}+$ & $\mathrm{LN}_{-}$ & $\mathrm{LN}+$ & $\mathrm{LN}-$ & $\mathrm{LN}+$ & LN- \\
\hline CD44s+ & 1 & 8 & 0 & 1 & 0 & 0 & 0 & 0 & 1 & 9 \\
\hline $\begin{array}{l}\mathrm{CD} 44 \mathrm{~s}- \\
P \text { value }\end{array}$ & 2 & 3 & 3 & 1 & 3 & 2 & 2 & 0 & $\begin{array}{l}10 \\
0.022\end{array}$ & 6 \\
\hline ECAD+ & 2 & 8 & 2 & 2 & 2 & 1 & 2 & 0 & 8 & 11 \\
\hline $\begin{array}{l}\mathrm{ECAD}- \\
P \text { value }\end{array}$ & 1 & 3 & 1 & 0 & 1 & 1 & 0 & 0 & $\begin{array}{l}3 \\
0.975\end{array}$ & 4 \\
\hline
\end{tabular}

Lymph nodes were available for evaluation in 26 of the 51 cases. 
for two carcinoids, all the other tumors were located either in the lung or gastrointestinal tract (Table 1). Of the 20 pulmonary carcinoids, 18 were typical and the other 2 were classified as atypical carcinoids according to the WHO classification (24). Of the 29 carcinoids from gastrointestinal tract, 25 were classified as classical type, showing trabecular and insular morphological features, and the other 4 (from appendix) were classified as goblet cell type. A total of 13 cases demonstrated either lymph node (10 patients) or visceral (2 patients) or both lymph node and visceral ( 1 patient) metastasis (Tables 2 and 3). No difference in the morphological features of carcinoids with and without metastasis was observed.

CD44s and ECAD expression were detected in $45 \%$ (23/51) and $63 \%(32 / 51)$ of carcinoid tumors, respectively (Table 1). Coexpression of the two adhesion molecules was seen in 19 tumors, and both markers were negative in 15 tumors, with only 4 tumors expressing only CD44s, and 13 tumors, only ECAD $(P=$ $.01)$. There was no significant difference in the expression of CD44s or ECAD in carcinoids derived from different sites. However, $85 \%$ of carcinoids (11 of 13) with known metastasis lacked CD44s expression compared with $45 \%$ of tumors (17 of 38) without demonstrated metastasis $(P=.030$; Table 2$)$. Similarly, in the subgroup of patients who had lymph nodes available for evaluation, CD44s negativity was more frequently observed in tumors with lymph node metastasis $(10 / 11)$ than in those with negative lymph nodes $(6 / 15 ; P=.022$; Table 3 and Fig. $1 \mathrm{~A}-1 \mathrm{D})$. No difference was observed with ECAD expression in tumors with and without metastasis. Furthermore, no significant difference in the expression of the two adhesion molecules was observed between tumors of different sizes or with respect to age of the patients (Table 2). All four goblet cell carcinoid tumors were positive for ECAD, but only two were positive for CD44s.

Carcinoid tumors in general demonstrated a high microvessel density (mean $160 \pm 82$; Table 4 and Fig. 1E). Microvessel density of carcinoid tumors of the lung (190 \pm 106$)$ was higher than that of tumors from other sites (142 \pm 59$)$, although the difference was not statistically significant. The goblet cell carcinoids were histologically less cellular and had a more myxoid background. These tumors had lower microvessel density than did other carcinoids $(P=$ .0195; Fig. 1F). Microvessel density was not significantly different in tumors with or without metastasis, whether they were compared in the whole series or in the subgroup with lymph node dissection.

\section{DISCUSSION}

The biological behavior of carcinoids, in general, is unpredictable, although size, location, and morpho- logical features may provide some clues regarding behavior. Recently, various other parameters have been evaluated as potential prognostic indicators for carcinoid tumors. Some parameters, such as proliferative activity and expression of growth factors have proved somewhat useful (6). Because cell adhesion molecules are considered important in tumor growth, invasion, and metastasis, we evaluated the prognostic value of these molecules in carcinoids arising from different sites and carcinoids with known metastasis. In this study, we found reduced expression of CD44s in tumors with metastasis. In contrast, the expression of ECAD showed no correlation with metastatic spread. Similarly, microvessel density also failed to distinguish carcinoid tumors by site or potential for metastatic spread. Although our clinical follow-up interval of 2 to 6 years is relatively short, outcome for our patients was good with 47 of the 51 patients alive and only 2 succumbing to the disease. Longer follow-up is required to more firmly establish the correlation between clinical outcome and the expression of the cell adhesion molecules and the effect of angiogenesis.

The role of CD44s and its various isoforms in tumorigenesis and tumor progression is very controversial. For example, loss of CD44s expression was reported to be associated with unfavorable outcome in patients with neuroblastoma (25), prostate carcinoma (26), transitional cell carcinoma of the bladder (27) and differentiated thyroid carcinoma (28).

However, opposite results have been reported in primary lung adenocarcinoma (29), colorectal cancer (30), and pancreatic endocrine tumors (5). The complexity of the biological function of the molecule, the small sample size in some studies, and the methods used to evaluate significance of these molecules may have all contributed to this controversy.

Reports on CD44 expression in carcinoid tumors are limited. Coppola and coworkers (6) showed decreased expression of CD44s and CD44v6 in atypical carcinoids and small cell carcinomas of the lung compared with the case of typical carcinoids. These investigators suggested that loss of CD44 expression correlated with more aggressive phenotypes. More recently, Granberg and coworkers $(8,9)$ demonstrated that expression of CD44s as well as CD44v7-8 and v9 was associated with decreased risk for distant metastases and with a more favorable outcome in patients who had typical carcinoids of the lung. In our series, we included not only carcinoid tumors from the lung but also those from other organs such as gastrointestinal tract. Our results showed that CD44s expression was more frequently negative in tumors with lymph node and/or visceral metastasis than in those without demonstrated metastasis $(P=.030)$. A statisti- 


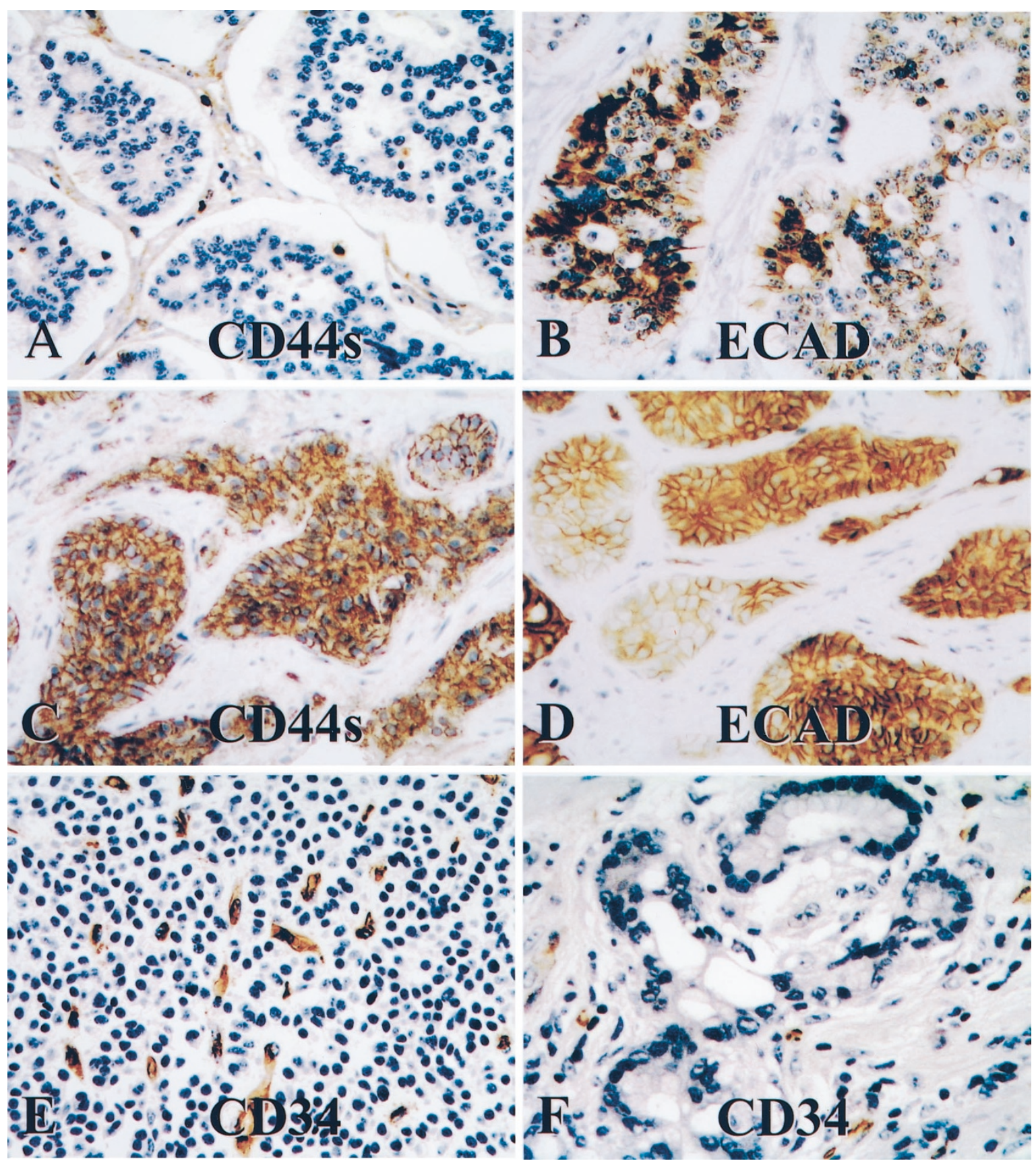

FIGURE 1. A and B, primary carcinoid tumor of colon from a 49-year-old male with known metastasis to two of seven lymph nodes. Cells lack CD44s expression but show membranous expression of ECAD. $\mathbf{C}$ and $\mathbf{D}$, diffuse membranous CD44s and ECAD expression in carcinoid tumor of the colon from a 50-year-old female with no tumor metastasis. E and F, Demonstration of MVD in carcinoid of colon (E) and goblet cell carcinoid of the appendix (F). In the goblet cell carcinoid, MVD (counted in five 200× fields) was low compared with the case of the typical carcinoid tumor (43 versus 256 ).

cally significant difference was also noted in the subgroup of 26 patients whose lymph node status was known $(P=.022)$. These findings further sup- port the concept that loss of the adhesion molecule plays a crucial role in tumor progression and metastases in carcinoids.

TABLE 4. Microvessel Density (MVD) in Carcinoid Tumors (per Five $200 \times$ Fields)

\begin{tabular}{|c|c|c|c|c|c|c|c|c|c|c|c|}
\hline Costo & $\mathrm{L}$ & SB & LB & A & $\mathrm{S}$ & $\mathrm{O}$ & $\mathrm{LN}+$ & $\mathrm{LN}-$ & Met+ & Met- & Gob \\
\hline & 19 & 6 & 10 & 6 & 5 & 2 & 11 & 15 & 13 & 38 & 4 \\
\hline $\mathrm{MVD} \pm \mathrm{SD}$ & $190 \pm 106$ & $163 \pm 59$ & $132 \pm 55$ & $110 \pm 61$ & $147 \pm 41$ & $210 \pm 50$ & $152 \pm 70$ & $198 \pm 96$ & $131 \pm 84$ & $163 \pm 82$ & $66 \pm 20$ \\
\hline
\end{tabular}

L, lung; SB, small bowel; LB, large bowel; A, appendix; S, stomach; O, other organs; LN+ or LN-, lymph node status; Met+ or Met-, with or without known metastasis. 
ECAD and the associated catenin complex play an integral role in epithelial cell adhesion. Reduced expression of ECAD has been associated with lymph node metastasis in various carcinomas (18, 21). In our series, ECAD expression correlated with CD44s expression, although more tumors were positive for ECAD than for CD44s. Unlike CD44s, ECAD expression was not significantly different in lymph node-positive and -negative groups. Although a larger series is needed to confirm this finding, different cell adhesion molecules may be involved in the regulation of metastatic spread of different tumors.

Clinical and experimental studies have shown that angiogenesis is a prerequisite for tumor growth and progression and has been correlated with metastasis in breast, prostate, and bladder carcinomas and in melanomas (31-33). Previous studies, however, failed to demonstrate correlation of angiogenesis with the metastatic potential of pulmonary carcinoid tumors (10). Our data also showed no statistically significant difference in MVD between tumor groups with or without lymph node metastasis or among tumors of various origins. Although the reason for this lack of correlation in carcinoid tumors is not known, factors other than MVD, which is normally high in carcinoid tumors, may be more important in controlling the metastatic process.

Acknowledgments: We thank Dr. W. B. Laskin for his comments on the manuscript and Carol Kiely for her assistance in immunohistochemical staining.

\section{REFERENCES}

1. Caplin ME, Buscombe JR, Hilson AJ, Jones AL, Watkinson AF, Burroughs AK. Carcinoid tumour. Lancet 1998;352:799-805.

2. Kulke MH, Mayer RJ. Carcinoid tumors. N Engl J Med 1999; 340:858-68.

3. Bukowski RM, Johnson KG, Peterson RF, Stephens RL, Rivkin $\mathrm{SE}$, Neilan B, et al. A phase II trial of combination chemotherapy in patients with metastatic carcinoid tumors. A Southwest Oncology Group Study. Cancer 1987;60:2891-5.

4. Engstrom PF, Lavin PT, Moertel CG, Folsch E, Douglass HO Jr. Streptocin plus fluorouracil versus doxorubicin therapy for metastatic carcinoid tumor. J Clin Oncol 1984;2:1255-9.

5. Chaudhry A, Gobl A, Eriksson B, Skogseid B, Oberg K. Different splice variants of CD44 are expressed in gastrinomas but not in other subtypes of endocrine pancreatic tumors. Cancer Res 1994;54:981-6.

6. Coppola D, Clarke M, Landreneau R, Weyant RJ, Cooper D, Yousem SA. Bcl-2, p53, CD44, and CD44v6 isoform expression in neuroendocrine tumors of the lung. Mod Pathol 1996;9:484-90.

7. Fasano M, Sabatini MT, Wieczorek R, Sidhu G, Goswami S, Jagirdar J. CD44 and its v6 spliced variant in lung tumors: a role in histogenesis? Cancer 1997;80:34-41.

8. Granberg D, Wilander E, Oberg K, Skogseid B. Prognostic markers in patients with typical bronchial carcinoid tumors. J Clin Endocrinol Metab 2000;85:3425-30.
9. Granberg D, Wilander E, Oberg K, Skogseid B. Decreased survival in patients with CD44-negative typical bronchial carcinoid tumors. Int J Cancer 1999;84:484-8.

10. Slodkowska J, Sikora J, Androsiuk W, Rudzinski P, Radomyski A. Lung carcinoids. Tumor angiogenesis in relation to clinicopathologic characteristics. Anal Quant Cytol Histol 1999; 21:267-72.

11. Sherman L, Sleeman J, Dall P, Hekele A, Moll J, Ponta H, et al. The CD44 proteins in embryonic development and in cancer. Curr Top Microbiol Immunol 1996;213:249-69.

12. Gunthert U, Hofmann M, Rudy W, et al. A new variant of glycoprotein CD44 confers metastatic potential to rat carcinoma cells. Cell 1991;65:13-24.

13. Sherman L, Sleeman J, Herrlich P, Ponta H. Hyaluronate receptors: key players in growth, differentiation, migration and tumor progression. Curr Opin Cell Biol 1994;6:726-33.

14. Lesley J, Hyman R, Kincade PW. CD44 and its interaction with extracellular matrix. Adv Immunol 1993;54:271-335.

15. Stamenkovic I, Amiot M, Pesando JM, Seed B. A lymphocyte molecule implicated in lymph node homing is a member of the cartilage link protein family. Cell 1989;56:1057-62.

16. Sneath RJ, Mangham DC. The normal structure and function of CD44 and its role in neoplasia. Mol Pathol 1998;51:191-200.

17. Herrlich P, Morrison H, Sleeman J, Orian-Rousseau V, Konig $\mathrm{H}$, Weg-Remers S, et al. CD44 acts both as a growth- and invasiveness-promoting molecule and as a tumorsuppressing cofactor. Ann NY Acad Sci 2000;910:106-20.

18. Koseki S, Aoki T, Ansai S, Hozumi Y, Mitsuhashi Y, Kondo S. An immunohistochemical study of E-cadherin expression in human squamous cell carcinoma of the skin: relationship between decreased expression of E-cadherin in the primary lesion and regional lymph node metastasis. J Dermatol 1999; 26:416-22.

19. Ramesh S, Nash J, McCulloch PG. Reduction in membranous expression of beta- catenin and increased cytoplasmic E-cadherin expression predict poor survival in gastric cancer. Br J Cancer 1999;81:1392-7.

20. Kimura T, Tanaka S, Haruma K, Sumii K, Kajiyama G, Shimamot F, et al. Clinical significance of MUC1 and E-cadherin expression, cellular proliferation, and angiogenesis at the deepest invasive portion of colorectal cancer. Int J Oncol 2000;16:55-64.

21. Kawanishi K, Doki Y, Shiozaki H, Yano M, Inoue M, Fukuchi $\mathrm{N}$, et al. Correlation between loss of E-cadherin expression and overexpression of autocrine motility factor receptor in association with progression of human gastric cancers. Am J Clin Pathol 2000;113:266-74.

22. Hsu SM, Raine L, Fanger H. Use of avidin-biotin-peroxidase complex (ABC) in immunoperoxidase techniques: a comparison between $\mathrm{ABC}$ and unlabeled antibody (PAP) procedures. J Histochem Cytochem 1981;29:577-80.

23. Mikami T, Mitomi H, Hara A, Yanagisawa N, Yoshida T, Tsuruta $\mathrm{O}$, et al. Decreased expression of CD44, alphacatenin, and deleted colon carcinoma and altered expression of beta-catenin in ulcerative colitis-associated dysplasia and carcinoma, as compared with sporadic colon neoplasms. Cancer 2000;89:733-40.

24. Travis WD, Colby TV, Corrin B, Shimosato Y, Brambilla E. WHO histological typing of lung and pleural tumors. 3rd ed. Geneva: World Health Organization; 1999.

25. Christiansen H, Sahin K, Berthold F, Hero B, Terpe HJ, Lampert F. Comparison of DNA aneuploidy, chromosome 1 abnormalities, MYCN amplification and CD44 expression as prognostic factors in neuroblastoma. Eur J Cancer 1995;31A: 541-4.

26. Aaltomaa S, Lipponen P, Viitanen J, Kankkunen JP, Ala-Opas M, Kosma VM. Prognostic value of CD44 standard, variant isoforms 3 and 6 and -catenin expression in local prostate 
cancer treated by radical prostatectomy. Eur Urol 2000;38: $555-62$.

27. Masuda M, Takano Y, Iki M, Makiyama K, Noguchi S, Hosaka M. Expression and prognostic value of CD44 isoforms in transitional cell carcinoma of renal pelvis and ureter. J Urol 1999;161:805-8; discussion 808-9.

28. Bohm JP, Niskanen LK, Pirinen RT, Kiraly K, Kellokoski JK, Moisio KI, et al. Reduced CD44 standard expression is associated with tumour recurrence and unfavourable outcome in differentiated thyroid carcinoma. J Pathol 2000; 192:321-7.

29. Takanami I, Takeuchi K, Naruke M. Expression and prognostic value of the standard CD44 protein in pulmonary adenocarcinoma. Oncol Rep 2000;7:1065-7.
30. Sumiyoshi Y, Yamashita Y, Maekawa T, Sakai N, Shirakusa T, Kikuchi M. Expression of CD44, vascular endothelial growth factor, and proliferating cell nuclear antigen in severe venous invasional colorectal cancer and its relationship to liver metastasis. Surg Today 2000;30:323-7.

31. Carmeliet P, Jain RK. Angiogenesis in cancer and other diseases. Nature 2000;407:249-57.

32. Gimbrone MA Jr, Cotran RS, Leapman SB, Folkman J. Tumor growth and neovascularization: an experimental model using the rabbit cornea. J Natl Cancer Inst 1974;52: 413-27.

33. Gimbrone MA Jr, Leapman SB, Cotran RS, Folkman J. Tumor dormancy in vivo by prevention of neovascularization. J Exp Med 1972;136:261-76. 